\title{
Parameters Identification and Estimation in Power System Based on Lagrange Multiplier and Variable Step Integration Algorithm
}

\author{
Xinyi Wang and Zhi Liu
}

\begin{abstract}
The parameter errors of power network can lead significantly deteriorate state estimation results in power system.In this paper, identification of suspicious parameters based on Lagrange multiplier is analyzed firstly. Then, a method of distinguishing the suspicious branch sets is proposed. Finally, the variable step integration algorithm is used to estimate the identified suspicious parameters. The proposed method has been deployed in several provincial power control centers to estimate the identified suspicious parameters. The experimental results illustrate the effectiveness of the proposed algorithm.
\end{abstract}

Index Terms-Power network, parameters identification and estimation, power system, state estimation.

\section{INTRODUCTION}

With the expansion of the scale of modern power system, the structure and operation mode of the power network is more and more complex. The dispatch system is required to obtain operation state and finish online decision-making and controlling accurately and quickly. In actual power system operation, the operating parameters of state estimation depend on the correctness of network parameters and measurement acquisition, which is of vital importance for the safe and stable operation of power system [1]. Identification of the improper parameters from the massive power network data and improving the quality of the basic data of dispatching automation effectively has become the bottleneck problem which restricting power system advanced application level for further improve. Currently, Error parameters identification methods mainly include 2 categories, which is sensitivity analysis and the augmented state estimation [2]. Measurement error, numerical condition and suspicious parameter settings of those methods is sensitive, so the identification effect is not stable.

The parameters identification and estimation of the power network model has become the key technology in intelligent power network system [3]. Identification and estimation of doubtful network parameters based on Lagrange multiplier and the variable step integration algorithm is proposed in this paper. Firstly, the suspicious branch set is obtained by calculating Lagrange multiplier. Secondly, the suspicious branch sets are divided into error telemetry set and error network parameter polluted telemetry set. Thirdly,_the deviation of measured value and state estimation value of error network parameter polluted telemetry set is calculated.

Manuscript received July 28, 2015; revised October 30, 2015.

Xinyi Wang is with Nanjing University of Aeronautics and Astronautics, Nanjing, China (e-mail: Email: 496627392@qq.com).

Zhi Liu is with the 28th Research Institute of China Electronic Technology Group Corporation, Nanjing, China (e-mail: liuzhi271692225@163.com).
Then, the variable step integration algorithm is used to estimate the parameters of the suspicious line and the optimal estimation value of the route parameter estimation table is selected as the modified parameter of the suspicious line. At last, the parameter identification and estimation method is applied to a provincial power dispatching center.

\section{IDENTIFICATION AND ESTIMATION OF SUSPICIOUS NETWORK BRANCHES}

\section{A. Identification of Suspicious Branch Method Based on Lagrange Multiplier}

As the most important data module in EMS (energy management system) of power system, redundancy of system usually measured in state estimation, which can eliminate random interference and improve the accuracy of the data [4], [5]. Firstly, the suspicious branch set should be determined in parameter estimation. Identification of suspicious branch set based on Lagrange multiplier is used in this paper. The parameters estimation problem modeled as follows :

$$
\left\{\begin{array}{l}
\min _{\boldsymbol{x}_{, p_{e}}} J(\boldsymbol{x})=\frac{1}{2} r^{T} W r \\
\text { s.t. } \quad c\left(\boldsymbol{x}, p_{e}\right)=0 \\
p_{e}=0
\end{array}\right.
$$

where, $\boldsymbol{r}=\boldsymbol{z}-\boldsymbol{h}\left(\boldsymbol{x}, p_{e}\right)$ is measured residual vector, $z$ is measurement vector, $h\left(x, p_{e}\right)$ is the nonlinear function vector of system state and line parameter error of the measurement system, $x$ is the state vector, including voltage amplitude and phase angle of voltage, $p_{e}$ is network parameter error vector, $W$ is weight diagonal matrix, $c\left(x, p_{e}\right)=0$ is zero injection node equality constraint, $p_{e}=0$ is equality constraints for parametric errors.

Construct the Lagrange multiplier as:

$$
L=\frac{1}{2} r^{\mathrm{T}} W r-\mu^{\mathrm{T}} c\left(x, p_{e}\right)-\lambda^{\mathrm{T}} p_{e}
$$

where, $\mu$ and $\lambda$ are the equality constraint of the zero injection node and the parameter error of Lagrange multiplier vector.

The procedure of doubtful network parameters identification based on Lagrange multiplier are given as follows [6]: 
1) Construction of least square estimation model.

2) Calculate the normalized residuals $r_{N}$ and the normalized Lagrange multipliers $N$ for the network parameter considering the result of the least square estimation based on step 1 .

3) If $\max \left|r_{N}, \lambda_{N}\right|<c$, there are no error network parameters and error telemetry, so exit calculation. $C$ is a constant set of artificial, usually can be valued 3 . If $\max \left|r_{N}, \lambda_{N}\right|>c$, then proceeding to step 4 .

4) If the large value of $r_{N}, \lambda_{N}$ corresponds to the regularization residuals $r_{N}$, then eliminating the corresponding measurement in the effective measurement set. If it is $\lambda_{N}$, which means the corresponding network parameters are wrong and shoule be modified and then return step 1).

Research shows that the method mentioned above can achieve good identification results. However, there are some difficulties for practical application. Repeated state and paramete estimation are needed to identify error telemetry and error network parameters, which needs a lot of calculation [7].

\section{Suspicious Parameters Set Division}

The network parameters of power system mainly include the static parameters such as reactance and resistance. It is very hard to get the correct power network parameters and the measurement data in the current power system, so it is of vital importance to identify error parameters or bad measurement data [8].

The measurement set of the state estimation is divided into the following 3 subsets.

1) Normal measurement set R. The actual state estimation contains the identification of bad data, which can divide the measurement set into normal measurement set $\mathrm{R}$ and the suspicious set $\mathrm{S}$.The measurement of set $\mathrm{R}$ participate in state estimation, while set $\mathrm{S}$ does not.

2) Error remote set E. Set of undesirable telemetry due to the error of measurement information maintenance, communication interference and other reasons.

3) Telemetry set I contains error parameters polluted by other error network parameters.

The parameters in set $\mathrm{E}$ should not be involved in parameters identification calculation of the measurement; otherwise it may lead to the error of network parameter identification. Parameters in set I should be involved, and it should be the important basis for the identification of network parameters[9], [10]. When there are mistakes in multiple intensity correlation data at the same time, we think it is the error of power network parameters, which leads to deviations between the results and the state estimates.

The huge additional computational quantity brought by the repeated state estimation can be avoided through this rule process, so that the calculation efficiency of network parameter identification is improved.

\section{A. Estimation of Suspicious Line Parameters}

After determination of suspicious branch sets and distinguishing the set I which contains error parameters polluted by other error network parameter, the estimation method of the variable step integral is used to estimate the parameters of each branch of set I [11], [12]. The parameters of the line are changed gradually by the step changing and the results of the calculation are obtained by using the state estimation calculation. The procedure of variable step integration algorithm for the resistance parameter estimation is given as follows[13], [14]:

1) Calculation of suspicious line deviation. Firstly, the deviation of the results of the reactive power estimation and the measurement of the suspicious line in the set I should be calculated. The reactive power deviation of uspicious line is as follows.

$$
E_{b}=\left(M-S_{e}\right) / 100
$$

where, $M$ is absolute value of branch reactive power measurement, $\mathrm{Se}$ is absolute value of the reactive state estimation of the branch. The deviation of the branch is:

$$
E_{x}=\operatorname{abs}\left(E_{b}\right)+0.1 \times M_{s e} .
$$

where, $M_{s e}$ is the unqualified points in state estimation.

2) Parameters prediction of suspicious line. During each iteration, if $E_{b}>0$, value of $X$ should be reduced. Otherwise, it should be increased. If the direction of $E_{b}$ is on the contrary to previous iterations in one iteration, then the tterative step should be halved. After all iterations, selecting one of the value of $x$ which make the minimum $E_{x}$ as a parameter estimate results.

3) Evaluation index Estimation. The deviation of the line is:

$$
E_{x}=\operatorname{abs}\left(E_{b}\right)+0.1 \times M_{s e} .
$$

Put predict resistance $X^{*}$, evaluation index $E_{X}$ and $E^{*}$ in route parameter estimation table. Repeat step (1) to (3) until the number of times of the default is reached.

4) Selection of parameter correction values. Select predict resistance $X^{*}$ which $E_{x}$ is minimum and $E^{*}<E_{0}$ as modified resistance. If the above conditions are not satisfied, then the line should be set as can not be estimated.

Reactance can be modified by changing the reactive power parameter to active power in above calculation step. According to the above parameters estimation method, the flow chart of power network parameter estimation algorithm in this paper is shown in Fig. 1.

\section{Simulation AND ANAlysis}

The identification method of the suspicious parameters based on the Lagrange multiplier is researched in this paper, moreover, the measurement set is divided. Then the parameters of the suspicious branch sets are generated by variable step integral method according to the result of dividing. Identification and estimation of error parameters in power network is realized in this paper and the basic data 
quality of scheduling automation is improved. Based on the parameter identification of power network research and practical demand, the example of a provincial electric power system is shown in Table I:

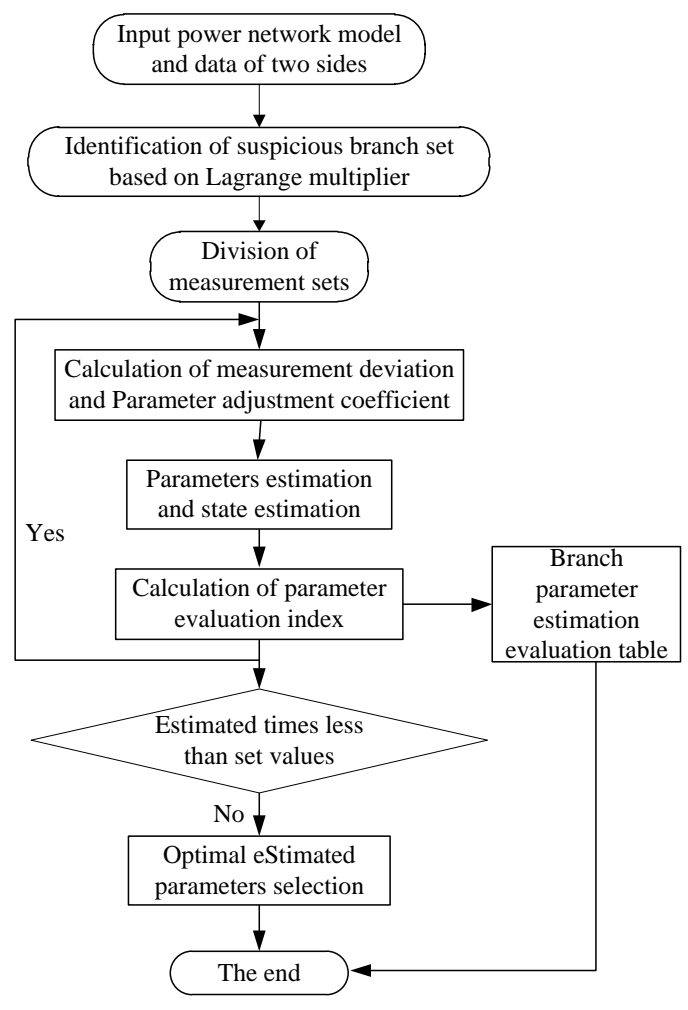

Fig. 1. Flow chart of the proposed algorithm.

TABLE I: VALUE OF REgULARIZATION LAGRANGE MULTIPLIER OF NETWORK PARAMETER

\begin{tabular}{|c|l|c|c|c|c|}
\hline No. & $\begin{array}{l}\text { Network } \\
\text { parameter name }\end{array}$ & $\begin{array}{c}\text { regularization } \\
\text { Lagrange } \\
\text { Multiplier }\end{array}$ & $\begin{array}{c}\text { Initial } \\
\text { value }\end{array}$ & $\begin{array}{c}\text { Estimated } \\
\text { value }\end{array}$ & The set \\
\hline 1 & $\begin{array}{l}\text { Reactance of } \\
\text { Luo Fu I line }\end{array}$ & 2.599 & 3.360 & 1.380 & $\mathrm{I}$ \\
\hline 2 & $\begin{array}{l}\text { Resistance of } \\
\text { Meng Luo I line }\end{array}$ & 2.267 & 0.097 & 1.567 & $\mathrm{I}$ \\
\hline 3 & $\begin{array}{l}\text { Resistance of } \\
\text { Meng Yong I } \\
\text { line }\end{array}$ & 2.802 & 0.096 & 1.256 & $\mathrm{I}$ \\
\hline 4 & $\begin{array}{l}\text { Reactance of Le } \\
\text { Tong I line }\end{array}$ & 3.156 & 0.678 & 1.354 & $\mathrm{R}$ \\
\hline 5 & $\begin{array}{l}\text { Reactance of Ci } \\
\text { Yong I line }\end{array}$ & 1.287 & 1.001 & 0.945 & $\mathrm{E}$ \\
\hline 6 & $\begin{array}{l}\text { Reactance of } \\
\text { Gui Tong I line }\end{array}$ & 1.212 & 1.932 & 1.162 & $\mathrm{E}$ \\
\hline
\end{tabular}

According to the identification method of suspicious line parameters, Luo Fu I line, Meng Luo I line and Meng Yong I line have not only large value of regularized multiplier but also large difference between the estimate and the initial values. The values above belong to set I with small measurement error, but the parameter errors cause large deviation of estimation, which should participate in the calculation of parameter estimation. Ci Yong line and Gui Tong line belong to set $\mathrm{E}$ of error measurement line caused by the fault of measurement equipments or communication interference, which should not participate in parameter estimation calculation.

The results show that the identification method of the power network parameters proposed in this paper can effectively identify the influence to state estimation caused by measurement error and parameters error.

TABLE II: THE MEASUREMENT RESULTS BEFORE THE NETWORK PARAMETER MODIFICATION IN A PROVINCIAL SYSTEM

\begin{tabular}{|c|c|c|c|c|}
\hline Branch name & $\begin{array}{l}\text { Measured } \\
\text { value } \\
\text { (MW/Mvar) }\end{array}$ & $\begin{array}{l}\text { Estimated } \\
\text { value } \\
\text { (MW/Mvar) }\end{array}$ & $\begin{array}{c}\text { Measure } \\
\text { ment } \\
\text { Deviation }\end{array}$ & $\begin{array}{l}\text { The } \\
\text { set }\end{array}$ \\
\hline $\begin{array}{l}\text { Active power of head } \\
\text { of Luo Fu I line }\end{array}$ & -346 & -268 & $7.49 \%$ & \multirow[b]{2}{*}{ I } \\
\hline $\begin{array}{c}\text { Active power of end of } \\
\text { Luo Fu I line }\end{array}$ & 320 & 266 & $7.84 \%$ & \\
\hline $\begin{array}{l}\text { Reactive power of } \\
\text { head of Meng Luo I } \\
\text { line }\end{array}$ & -110 & -174 & $5.62 \%$ & \multirow[t]{2}{*}{ I } \\
\hline $\begin{array}{c}\text { Reactive power of end } \\
\text { of Meng Luo I line }\end{array}$ & 5 & 44 & $3.85 \%$ & \\
\hline $\begin{array}{c}\text { Reactive power of } \\
\text { head of Meng Yong I } \\
\text { line }\end{array}$ & -54 & -17 & $4.51 \%$ & \multirow[t]{2}{*}{ I } \\
\hline $\begin{array}{c}\text { Reactive power of end } \\
\text { of Meng Yong I line }\end{array}$ & -16 & -87 & $6.46 \%$ & \\
\hline
\end{tabular}

The measurement results before network parameter modification and state estimation in a provincial electric power system are shown in Table $\Pi$.

The estimation iterative process of parameters of Mon Luo I line are shown in Table III. After multiple calculation of parameter estimation iteration of this line, we can get the large error points and average measurement deviation. According to selection criteria of parameter correction, estimate value in the second iteration of Meng Luo I line is the optimal estimate value from Table $I$, which means resistance parameter should be adjusted from 0.3 to 0.025 as the parameter modify value.

\begin{tabular}{|c|c|c|c|c|}
\hline \multicolumn{3}{|c|}{ TABLE III: PROCESS OF MENG LUO I LINE PARAMETER ESTIMATION } \\
\hline $\begin{array}{c}\text { Iterative } \\
\text { number }\end{array}$ & $\begin{array}{c}\text { Value of head } \\
\text { estimate }\end{array}$ & $\begin{array}{c}\text { Value of } \\
\text { end estimate }\end{array}$ & $\begin{array}{c}\text { Estimated } \\
\text { value }\end{array}$ & $\begin{array}{c}\text { Unqualified } \\
\text { points } \\
\text { (Deviation) }\end{array}$ \\
\hline 0 & -154.17 & 21.97 & 0.210 & $16(0.42 \%)$ \\
\hline 1 & -138.37 & 6.19 & 0.147 & $15(0.26 \%)$ \\
\hline 2 & -129.12 & -3.07 & 0.103 & $15(0.17 \%)$ \\
\hline 3 & -122.55 & -9.66 & 0.072 & $15(0.11 \%)$ \\
\hline 4 & -117.90 & -14.33 & 0.050 & $15(0.06 \%)$ \\
\hline 5 & -114.64. & -17.61 & 0.035 & $15(0.03 \%)$ \\
\hline 6 & -122.34 & -19.92 & 0.025 & $15(0.00 \%)$ \\
\hline 7 & -110.73 & -21.54 & 0.017 & $15(0.01 \%)$ \\
\hline
\end{tabular}

The comparison of network parameters of Luo Fu No.1 line, Meng Luo No.1 line and Meng Yong No.1 line before and after the correction is shown in Table IV and in Table V. Table IV shows that after modification, the deviation of the first and the end of the measurement is small in parameter error line. From Table IV we can see that after network parameter modification, the qualified rate of the power line is significantly improved and the deviation values were significantly decreased. From the results of Table IV and in Table $\mathrm{V}$ we can see, the power network parameter identification and estimation method in this paper is correct and effective. 
TABLE IV: COMPARISON OF THE RELATIVE MEASUREMENT DEVIATION BEFORE AND AFTER THE PARAMETER MODIFICATION

\begin{tabular}{|c|c|c|c|c|c|c|}
\hline Line & $\begin{array}{c}\text { Value of line } \\
\text { head } \\
\text { (MW/Mvar) }\end{array}$ & $\begin{array}{c}\text { Estimate value of } \\
\text { line head } \\
(\mathrm{MW} / \mathrm{Mvar})\end{array}$ & $\begin{array}{l}\text { Value of line } \\
\text { end } \\
\text { (MW/Mvar) }\end{array}$ & $\begin{array}{c}\text { Estimate value } \\
\text { of line end } \\
\text { (MW/Mvar) }\end{array}$ & $\begin{array}{c}\text { Deviation } \\
\text { Of line head }\end{array}$ & $\begin{array}{l}\text { Deviation } \\
\text { Of line end }\end{array}$ \\
\hline $\begin{array}{l}\text { Luo Fu I line before } \\
\text { modification }\end{array}$ & -334 & -256 & 330 & 256 & $7.39 \%$ & $6.84 \%$ \\
\hline $\begin{array}{l}\text { Luo Fu I line after } \\
\text { modification }\end{array}$ & -326 & -325 & 332 & 334 & $0.09 \%$ & $0.55 \%$ \\
\hline $\begin{array}{l}\text { Meng Luo I line before } \\
\text { modification }\end{array}$ & -114 & -175 & 1 & 43 & $5.82 \%$ & $3.88 \%$ \\
\hline $\begin{array}{l}\text { Meng Luo I line after } \\
\text { modification }\end{array}$ & -114 & -114 & 1 & -2 & $0.00 \%$ & $0.28 \%$ \\
\hline $\begin{array}{l}\text { Meng Yong I line before } \\
\text { modification }\end{array}$ & -53 & -14 & -14 & -85 & $3.51 \%$ & $6.56 \%$ \\
\hline $\begin{array}{l}\text { Meng Yong I line after } \\
\text { modification }\end{array}$ & -53 & -53 & -14 & -15 & $0.00 \%$ & $0.09 \%$ \\
\hline
\end{tabular}

TABLE V: COMPARISON OF EVALUATION INDEX BEFORE AND AFTER THE PARAMETER MODIFICATION

\begin{tabular}{|c|c|c|c|c|c|c|c|}
\hline Line & $\begin{array}{c}\text { Initial } \\
\text { value }\end{array}$ & $\begin{array}{c}\text { Unqualified points } \\
\text { before modification }\end{array}$ & $\begin{array}{c}\text { Qualified rate } \\
\text { before } \\
\text { modification }\end{array}$ & $\begin{array}{c}\text { Deviation } \\
\text { before } \\
\text { modification }\end{array}$ & $\begin{array}{c}\text { Value after } \\
\text { modification }\end{array}$ & $\begin{array}{c}\text { Unqualified } \\
\text { points after } \\
\text { modification } \\
\text { rate after } \\
\text { modificatio } \\
\mathrm{n}\end{array}$ & $\begin{array}{c}\text { Deviation } \\
\text { after } \\
\text { modificatio } \\
\mathrm{n}\end{array}$ \\
\hline Luo Fu I line & 2 & 24 & $99.1 \%$ & $7.15 \%$ & 1.28 & 15 & $99.53 \%$ \\
\hline $\begin{array}{c}\text { Meng Luo I } \\
\text { line }\end{array}$ & 0.3 & 19 & $99.17 \%$ & $4.75 \%$ & 0.025 & 15 & $99.46 \%$ \\
\hline $\begin{array}{c}\text { Meng Yong I } \\
\text { line }\end{array}$ & 100 & 17 & $99.35 \%$ & $5.14 \%$ & 33.34 & $0.14 \%$ \\
\hline
\end{tabular}

\section{CONCLUSION}

Identification and estimation of doubtful network parameters based on Lagrange multiplier and the variable step integration algorithm is proposed in this paper. Only those parameters of correct measurement are considered in estimation, which avoids the influence of measurement error to the results of estimation. The parameters are changing by variable step integration algorithm, and the optimal value of the parameter estimation table is selected as the correction value of suspicious lines.

Finally, the proposed algorithm is applied in the operation of an actual power system. The results demonstrate the reliability and effectiveness of our algorithm.

\section{ACKNOWLEDGMENT}

First and foremost, I am deeply indebted to Liu Zhi, who guided me throughout my writing of this thesis. I am also grateful to Dr.Chen Xueqiang. He carefully read the whole draft and offered precious criticism. Their valuable instruction has benefited me a great deal.

Last but not least, I wish to sincerely thank electrical and electronic experiment center of Nanjing University of Aeronautics \& Astronautics creating a conducive environment for scientific research.

\section{REFERENCES}

[1] F. C. Schweppe and L. J. Wildes, "Power system static state estimation, part I:exact model," IEEE Trans on Power Apparatus and Systems, pp. 120-125 .

[2] L. Mili, M. G. Cheniae, N. S. Vichare et al., "Robust state estimation based on projection statistics," IEEE Trans on Power Systems, pp. 1118-1127, 1996.

[3] W. W. Kotiuga and M. Vidyasagar, "Bad data rejection properties of Strengthen power system security to ensure reliable power delivery," Power System Technology, 2003, vol. 27, no. 10, pp. 1-7.
[4] Z. X. Han and Y. J. Cao, "Power system security and its prevention," Power System Technology, vol. 28, no. 9, pp. 1-6, 2004.

[5] P. Zarco and A. G. Exposito, "Power system parameter estimation: A survey," IEEE Trans on Power Systems, 2000, vol. 15, no. 1, pp. 216222.

[6] Y. Guo, W. C. Wu, B. M. Zhang, H. B. Sun, "Power system network parameter error identification by lagrange multiplier based method," in Proc. the CSEE, 2013, vol. 33, no. 10, pp. 43-49.

[7] L. Mili, V. Phaniraj, and P. J. Rousseeuw, "Least median of squares estimation in power systems," IEEE Trans on Power Systems, 1991, pp. 511-523.

[8] Y. Guo, W. C. Wu, and B. M. Zhang, "A robust state estimation method with exponential objective function," in Proc. the CSEE, 2011, vol. 31, no. 4, pp. 67-71.

[9] B. Zeng, W. C. Wu, and B. M. Zhang, "A method to identify and estimate network parameter errors based on karush-kuhn-tucker condition," Power System Technology, 2010, vol. 34, no. 1, pp. 56-61.

[10] X. Z. Zhao, "Strengthen power system security to ensure reliable power delivery," Power System Technology, 2003, vol. 27, no. 10), pp. $1-7$.

[11] T. V. Cutsem and V. Quintana, "Network parameter estimation using online data with application to transformer tapposition estimation," in Proc. Institution of Electrical Engineers, 1988, vol. 135, no. 1, pp. 31-40.

[12] O. Alsac, N. Vempati, B. Stott et al., "Generalized state estimation," IEEE Trans. on Power Systems, 1998, vol. 13, no. 3, pp. 1069-1075.

[13] W. H. E. Liu, F. F. Wu, and S. M. Liu, "Parameter erroridentification and estimation in power system stateestimation," IEEE Trans. on Power Systems, 2006, vol. 21, no. 2, pp. 586-592.

[14] P. M. Anderson and A. A. Fouad, Power System Control and Stability, Ames, Iowa: The Iowa State University Press, 1977, pp. 37-39.

Xinyi Wang was born in 1987. She is an engineer at electrical and electronic experiment center of Nanjing University of Aeronautics and Astronautics, Nanjing, China. Her major field of study is electronic circuit.

Zhi Liu was born in 1984. He is an engineer at the 28th Research Institute of China Electronic Technology Group Corporation, Nanjing, China. His research field is power system analysis. 